\title{
Sürdürülebilir Kırsal Kalkınmada Bir Alternatif Olarak Kadın Girişimciliği: Afyonkarahisar Örneği*
}

Berfu ÍLTER ${ }^{1}$ Sabriye KUNDAK ${ }^{2}$ Vildan Saba CENIKLI ${ }^{3}$

Kırsal kalkınmanın nihai amaçlarından biri; ülkemizin tüm kırsal alanlarında yaşayan kadınların istihdamının girişimcilik yönünde gelişmesi sağlanarak yaşam standartlarının arttırılması ve kentlerde yaşayan kadınların yaşam standartlarına yaklaşmalarını mümkün kılmaktır. Çalışmanın amacı son zamanlarda gelişme gösteren kadın giriş̧imciliğinin, kırsal kalkınmanın sürdürülebilirliği açısından önemini ortaya koymaktır. Günümüz koşullarında genel bir kalkınma anlayışının ötesinde, yerel kaynakların değerlendirildiği kırsal kalkınma gelişmekte olan ülkeler için bir rekabet avantajı sunmaktadır. Bu anlamda kadın istihdamının kırsalda güçlendirilmesi için girișimcilik uygulamalarının teşvik edilmesi ve ekonomideki tüm kurumların iş birliği içinde bulunmaları önem arz etmektedir. Bu çerçevede; Afyonkarahisar ilinde kırsal kesimdeki kadınların girişimciliğini artırmaya yönelik uygulamalar ve uygulamaların sonuçları değerlendirilmiştir. Sonuç olarak T.C Tarım ve Orman Bakanlığı bünyesindeki Afyonkarahisar Il Tarım ve Orman Müdürlü̈̆̈̈ tarafindan gerçekleştirilen projeler sayesinde kırsal alanda yaşayan kadınların girişimcilik anlamında kendilerini ifade etmelerine firsat verildiğinde aynı zamanda kentte yaşayan kadınların sahip olmuş olduğu teknik sosyal ve ekonomik donanımlar să̆landığında bu alanda başarılı olabilecekleri kanaatine ulaşılmıştır.
\end{abstract}

Anahtar Kelimeler: Girişimcilik, Kırsal Kalkınma, Kadın istihdamı.

\section{The Entrepreneurship of Women as an Alternative for the Sustainable Rural Development: A Sample of Afyonkarahisar}

\begin{abstract}
One of the ultimate goals in rural development is to increase the standard of living of women living in all rural areas of our country by enabling their employment to develop towards entrepreneurship and to make it possible for these women to approach their life standards to the ones of the women living in urban areas. The aim of the present study was to demonstrate the importance of women entrepreneurship developing lately, in terms of the sustainability of rural development. Beyond a general understanding of development in today's conditions, rural development where local resources are assessed offers a competitive advantage for the developing countries. In this sense, it is important that entrepreneurship practices be encouraged in order to strengthen women's employment in rural areas and all institutions in the economy cooperate with each other. In this context, the applications for increasing women's entrepreneurship in the rural areas of Afyonkarahisar province and their results will be evaluated. As a result, thanks to the projects carried out by Afyonkarahisar Provincial Directorate of Agriculture and Forestry within the Ministry of Agriculture and Forestry; if rural women are given the opportunities to express themselves in the sense of entrepreneurship and the social and economic equipment provided by women living in the city are provided it is believed that they may be successful in this field.
\end{abstract}

Keywords: Entrepreneurship, Rural Development, Women's Employment.

\footnotetext{
* Bu çalışma, 26-29 Nisan 2018 tarihinde gerçekleştirilen "Innovation and Global Issues in Social Sciences III”de sunulan bildirinin genişletilmiş halidir.

${ }^{1}$ Dr. Öğr. Üyesi, Afyon Kocatepe Üniversitesi, İ̈BF, Uluslararası Ticaret ve Finans Bölümü, e-mail: berfu13@hotmail.com ORCID: 0000-0001-8738-1675

${ }^{2}$ Arș. Gör. Dr. Afyon Kocatepe Üniversitesi, İ̈BF, İktisat Bölümü, e-mail: sabriyebozok@aku.edu.tr

ORCID: 0000-0001-6135-6412

${ }^{3}$ Arş. Gör., Afyon Kocatepe Üniversitesi, İ̈BF, İktisat Bölümü, e-mail: saktop@aku.edu.tr

ORCID: 0000-0002-5636-5290
} 


\section{Giriş}

Gelişmekte olan ülkelerde aile işgücüne dayanan aile işletmeleri ve işletme sahipleri tarım işletmeleri olarak tanımlanmaktadır. Dolayısıyla kadınlar tarımda aktif rol alarak eşlerine yardımcı olmaktadırlar ve böylelikle tarım işletmelerinde aktif olarak çalışan kadın sayısı günden güne artmaktadır. Ancak bu kadınların çoğu "ücretsiz aile işgücü” olarak çalışmaktadır (Oğuz, 2015: 65).

Kırsal alanda kadınların arasında yaptıkları faaliyetler sonucunda gelir elde edebilenlerin sayısı oldukça azdır. Ev kadınları; tarımsal faaliyetler sonucunda elde ettikleri ürünleri pazarlayarak gelir elde edebilmektedirler. Ancak gelenekler ve toplumsal baskı, kadınların ve genç kızların emeğini gelir sağlama amacıyla kiralamasını engellemektedir. Emeğini kiralayarak gelir elde edenler ise dul ve evin geçimini sağlamak zorunda olan kadınlar, göç ile şehire yerleşen kadınlar ve mevsimlik işçilerdir. (T.C. Gıda Tarım ve Hayvancılık Bakanlığg, 2012: 12).

Türkiye'de de tüm dünyada olduğu gibi kırsalda yoksulluktan en fazla kadınlar etkilenmektedir. Kırsal alanlarda en az erkekler kadar kadınlarda performans göstermektedir. Ancak toplumsal ve ekonomik kalkınmanın imkânlarından yeterli miktarda fayda sağlayamamaktadırlar (Gülçubuk vd., 2012:358). Bu nedenle, kırsal alanda kalkınmanın gerçekleşmesi ve sosyo ekonomik gelişiminin sağlanabilmesi için; kadınların gelir elde etmesini sağlayacak girişimcilik faaliyetlerinde bulunmaları, pazarlama faaliyetlerinde bulunmaları ve kredi olanaklarına kolaylıkla ulaşmaları gerekmektedir (T.C. Gıda Tarım ve Hayvancılık Bakanlığı, 2012: 68). Bu kapsamda girişimcilikleri çoğu zaman göz ardı edilen kadınların, girişimcilik konusunda teşvik edilmeleri, kadınlara yönelik örgütlenmelerin daha etkin bir biçimde desteklenmeleri gerekmektedir.

Çalışma üç bölümden oluşmaktadır. Çalışmamızın ilk bölümünde sürdürülebilir kırsal kalkınma, ikinci bölümünde kırsalda kadın girişimciliği ve son bölümünde de Afyonkarahisar kırsalda kadın girişimciliği uygulamalarına yer verilmiştir.

\section{Sürdürülebilir Kırsal Kalkınma}

Kırsal alanlarda kültürel ve toplumsal süreçler yavaş gelişme göstermektedir. Gelenekler toplumsal hayatı oldukça fazla etkilemektedir. Teknolojik gelişmeler gündelik yaşama ve üretime uzun vadede yansımaktadır. Yüz yüze ilişkiler önem kazanmakta ve ekonomik hayatı ve yaşamı doğal kaynaklar belirlemektedir (DPT, 2000).

Kalkınma; az gelişmiş ülkelerin gelişmesi anlamında kullanılmakta olup toplum genelinde gerçekleşen refah göstergelerindeki iyileşmeler ve katma değer artışlarıdır. Gelişmekte olan ülkelerin gelişmekte olan ülkelerle aralarındaki farkı kapatabilmeleri için ekonomik, kültürel, sosyal açıdan karşılaştıkları yapısal sorunları aşmaları gerekmektedir. Yapısal engellerin aşılabilmesi için akılcı ve uzun soluklu çabalara ihtiyaç vardır. Bu anlamda kırsal kalkınma önem kazanmaktadır. Kırsal kalkınma, genel kalkınma programlarında yer almaktadır. Bölgesel kalkınma açısından kırsal kalkınma önem arz etmektedir.

Kırsal kalkınma faaliyetleri, kent ve kırsal arasındaki yaşam standart farklılıklarını, kırsal alanlarda yaşayanların yaşam koşullarını, ekonomik durumlarını güçlendirmek, sosyal ve kültürel yönden gelişimlerine katkıda bulunmak, bireylerin kontrolünde faaliyet gösterecek sosyal ve ekonomik birimler oluşturarak, kırsal yaşam standartlarını daha modern hale getirme hedefleri taşımaktadır (Doğanay, 1993:33). 
Günümüzde genel anlamdaki ekonomik kalkınma anlayışından daha çok sürdürülebilir kırsal kalkınma önem kazanmaktadır. Kalkınma, büyümeyi de içine alan ancak büyümeden daha kapsamlı bir kavramdır. Bu kavramda günümüz koşullarının yanı sıra gelecek kuşaklar da dikkate alınmaktadır. Tüm ülkelerin insanı ve çevreyi dikkate alan üretim yapılarını tercih etmeleri ve bu yönde insan kaynaklarını geliştirilmesine yönelik bir yapılanmayı kapsamaktadır. Kırsal kalkınma üç farklı açıdan değerlendirmektedir. Birincisi; sağlık, eğitim, kamu hizmetleri, kültürel miras, barınma, liderlik kapasitesi gibi kırsalda yaşayanların ve mekânların yaşamsallığını kapsar. İkincisi; sürdürülebilir olarak sosyal, kültürel, ekonomik ve çevresel hedeflere uyumlu olmaya çalışan çok yönlü bir süreçtir. Üçüncüsü; sosyal, ekonomik, kültürel ve çevresel değişiklikler sonucunda gerçekleşen sürdürülebilirlik uzun vadede toplum için refah yaratan bir değerdir (Moseley; 2003;4).

Kırsal kalkınmada en önemli yapı taşlarından birisini tarım oluşturmaktadır. Tarım sektörü, ekonomide önemli ölçüde istihdam yarattığ 1 ve kırsal alanlarda yaşayan insanlar için önemli bir gelir kaynağı olduğu için devlet tarafından desteklenmektedir. Kırsal kalkınma anlamında tarımsal politikalar uygulanmakta, toprak reformu gibi kurumsal gelişmeler sağlanmakta ve tarımda modern teknolojilerin kullanımı desteklenmektedir. Kadının tarımsal faaliyetlerdeki önemli rolüne rağmen girişimci anlamında zayıf kalması nedeniyle kırsal alanda kadın girişimciliği de sürdürülebilir kırsal kalkınma anlamında desteklenmektedir.

\section{Kırsal Alanda Kadın Girişimciliği}

Kadınlar üretim faaliyetlerinin her bir aşamasında aktif rol üstlenmelerine rağmen, kalkınmanın faydalarından tam anlamıyla yararlanamamaktadırlar. Bunun nedeni eğitim olanaklarından yoksun olmalarıdır. Ülkemizde kırsal alanda yaşamakta olan kadınların eğitim koşulları daha zor olmaktadır. Kadın işgücü erkek işgücüne göre tarımsal üretimde daha çok katkı sağlamasına rağmen, bu katkıları ekonomik anlamda resmi kaynaklara yansıtılmamaktadır. Günümüz şartlarında kırsal alandaki kadınlara yönelik gerçekleştirilen projelerin öncelikle beceri geliştirme, okuma-yazma öğretme ve pazara yönelik üretim temelinde gelir elde etme amacına dayandırılmaktadır. (Özgen ve Ufuk, 2011:1063). Bu bağlamda kadınların ücretli işgücü piyasasına girebilmesi ve kendi işinin sahibi girişimci kadınlar olabilmelerinde eğitim oldukça önemli rol oynamaktadır.

Kadın girişimci tanım olarak, TESK (Esnaf ve Sanatkârlar Birlikleri ve Odaları)'e ya da TOBB (Ticaret Odaları, Sanayi Odaları, Ticaret ve Sanayi Odaların)'a üye olan ve sosyal güvenlik kurumlarından herhangi birisine bağlı olan, piyasa ekonomisi içinde riskleri göze alabilen, doğrudan doğruya pazara yönelik, kazanca dönüşebilen, mal ve hizmet üreterek satabilen, ya da başka kişileri istihdam ederek işveren konumunda bulunan kişi olarak tanımlanmaktadır (Müftüoğlu ve Durukan, 2004: 35).

Aynı zamanda kadın girişimci tanımını şu şekilde ifade etmek mümkündür (Ecevit, 1993: 20):

- Kadın girişimci, kendi adına kurduğu ev dışında bir mekânda, bir ya da birkaç işyeri sahibi olan,

- Bu işyerinde sadece kendisi ya da istihdam ettiği diğer kişilerle bir arada çalışan ve/veya işyeri sahibi olarak ortaklık kuran,

- Herhangi bir ürün ya da hizmetin sunulması ve üretilmesi ile ilgili faaliyetlerde bulunarak, bu ürün ya da hizmetin pazarlama ve satışını bizzat yapan ya da yaptıran, 
- İş ile ilgili olarak görüşülmesi gerektiğinde doğrudan kişi, örgüt, kurum ve kuruluşlarla irtibata geçerek kendi adına görüşebilen,

- İş sürecinin örgütlenmesi, ürün ve hizmet sunum ya da üretiminin planlanması, iş yerinin faaliyete geçirilmesi, faaliyetin son bulması ya da işin geliştirilmesi konularında kendi karar alabilen,

- Faaliyetleri sonucu elde ettiği kazancın kullanım ve yatırım konularında söz sahibi olan kişidir.

Dolayısıyla kadın girişimciyi; evinin dışında bir mekânda, kendi adına ya da ortak olarak, bir ya da birkaç işyeri olan, herhangi bir ürün ya da hizmetin sunulması-üretilmesi, pazarlanması ve tüm işletme faaliyetleri hususunda kararlar alan, uygulayan, gerçek ve tüzel kişiler ile kendi adına ilişki kuran ve işinden elde ettiği kazancın kullanımı konusunda söz sahibi olan kişi olarak ifade etmek mümkündür (İter, 2010: 67). Ancak burada "evinin dişında" ifadesinin güncellenmesi gerekmektedir. Çünkü günümüzün iletişim ve teknolojik gelişmeleri göz önüne alındığında, girişimcilik faaliyetlerinin ev içi ya da ev dışında da gerçekleştirilmesi mümkün görülmektedir. Ayrıca günümüzde ev eksenli çalışmalar da kadın girişimciliğini destekleyen yaklaşımlar arasında yer almaktadır.

Türkiye'de kırsal kesimde kadın girişimciliği faaliyetinden bahsetmek mümkün değildir. Çünkü kırsal kesimde yapılan çalışmalar genellikle kalkınma çalışmaları içinde yer almakta ve kadını kişisel olarak geliştirmeyi amaçlayan - halıcılık, konserve yapımı, ev ekonomisi vb faaliyetler- uygulamalar olarak yer almaktadır. Bu nedenle kırsal kesimde gerçek anlamda kırsal kadın girişimciliği uygulamasından söz etmek mümkün değildir. Çünkü Türkiye'de herhangi bir kuruma resmi olarak kayıtlı olmayan kişiler istatistiksel olarak girişimci değerlendirilmesinin dışında kalmakta ve kayıt dışı küçük uygulamalar girişimcilik olarak görülmemektedir. Aynı zamanda bu küçük çabalar, toplum tarafindan boş zaman uğraşıları olarak görülmekte ve girişimcilik kapsamında düşünülmemektedir. Girişimcilik koşulu olarak; kadınların üretim/hizmetin başlamasından itibaren her aşamada; aktif katılımcı, karar verici ve denetim sahibi olduğu düşünüldüğünde; kırsal alandaki kadınların da girişimci olarak kabul edilmesi gerekmektedir. Kırsal alanda üretim çabalarına yoğun olarak katılan kadınlar, gelişmekte olan ülkelerde kırsal ekonomi için temel güç kaynağı olarak görülmektedirler. Ancak bu güç kaynağ 1 genellikle karşıllğı ödenmeyen «ücretsiz aile işçisi» olarak, ya da işgücü olarak değerlendirilirler. Girişimci niteliğini kazanabilecekleri pozisyona dahil edilmezler. Eğer kadınlarda bu süreçte; üretimden satışa kadar tüm aşamalarda karar verici pozisyonuna geldiklerinde girişimcilik faaliyetinden söz etmek mümkündür (Kantar, 1999: 36-37). Dolayısıyla kadınların girişimci olabilmeleri için tarımsal faaliyetlerin her adımında söz sahibi olmaları sağlanmalıdır.

Türkiye'de kırsal alandan ve kırsal alanda yaşayan kadının kendisinden kaynaklanan sorunlar kadının ekonomik hayatın dışında kalmasında etkili olabilmektedir (Soysal, 2013:171). Ancak gelişmekte olan toplumlarda, kadınların potansiyel güçlerini daha akılcı kullanılması sayesinde; sosyal kalkınma ve refah düzeyinin yükselebileceği görüşü genel olarak kabul görmektedir. Yapılması gereken bu görüşü destekleyen ve toplumda kadını hak ettiği olması gereken konuma taşıyacak politikaların hayata geçirilmesidir (Özgen ve Ufuk, 2011:1064).

Türkiye'de T.C. Gıda Tarım ve Hayvancılık Bakanlığg "Kırsal Alanda Kadının Güçlendirilmesi” ulusal eylem planını 2012-2016 yılları arasında uygulamıştır. Bu plan çerçevesinde; kırsal alanda yaşayan kadınlara tarımsal konularda bilgi ve tekniğin öğretilmesi, mevcut potansiyelin ortaya çıkarılarak bilgi ve becerilerinin geliştirilmesi, toplumda bu konuda 
çalışan paydaşları bir araya getirerek farkındalık oluşturulması, sorunların tespit edilerek uygun çözüm yolları ve politikalar geliştirilmiştir (Oğuz, 2015:65).

\section{Afyonkarahisar Örneği}

Türkiye' de Gıda Tarım ve Hayvancılık Bakanlığı tarafından uygulanan «Kırsal Alanda Kadının Güçlendirilmesi Eylem Planı» içeriğinde; kadınlara tarımın her alanında eğitimler verilmiştir. $\mathrm{Bu}$ eğitimler ile üretici ve girişimci ruha sahip kadınları bilgilendirmek, uygulanabilecek projelerin hayata geçirilmesi amaçlanmıştır. Bakanlık tarafindan bu eğitimler çerçevesinde gerçekleştirilen projeler aşağıda yer almaktadır. Afyonkarahisar' da uygulanan projeler ile ilgili bilgi, kaynakçada yer alan proje kitapçıklarından elde edilmiştir.

\section{1. "Yeni Geliştirilen Kuru Fasulye Çeşitlerinin ve Yetiştirme Tekniklerinin Afyonkarahisar İli Kadın Çiftçilerine Yayımı" Projesi}

Bakanlık Afyonkarahisar Valiliği İl Gıda Tarım ve Hayvancılık Müdürlüğ̈ 2016 yılında "Kadın Çiftçiler Tarımsal Yayım Projesi” uygulamaya konulmuştur. Proje kapsamında; tarım alanında yoğun olarak faaliyet gösteren fakat yeniliklerden ve gelişen teknolojilerden en az düzeyde yararlanan kadın çiftçilerin tarımsal alanda daha verimli olabilmesi, tarımsal yeniliklerden zamanında yararlanabilmesi, yeni teknolojileri öğrenmesi ve uygulaması, kaynakları daha etkili kullanması ve yeniliklerin kadın çiftçi merkezli yayılmasını sağlamak amaçlanmıştır. Proje, "Eskişehir Geçit Kuşağı Tarımsal Araştırma Enstitüsü Müdürlüğü” ile işbirliği içerisinde yürütülmüştür. Bu işbirliği çerçevesinde "Yeni Geliştirilen Kuru Fasulye Çeşitlerinin ve Yetiştirme Tekniklerinin Afyonkarahisar İli Kadın Çiftçilerine Yayımı” Projesi hazırlanarak bakanlık tarafından onaylanmıştır.

2017 yılında proje konusu kapsamında kadın çiftçi eğitim toplantıları yapılmıştır. Proje 1 Ocak 31 Aralık 2017 arasında uygulanmıştır. Proje Afyonkarahisar ili;

- Sinanpaşa ilçesine bağlı Ahmetpaşa Kasabası,

- $\quad$ Tinaztepe Kasabas1

- $\quad$ Tokuşlar Köy’ünde uygulanmıştır.

"Kadın Çiftçiler Tarımsal Yeniliklerle Buluşuyor" programı kapsamında "Kuru Fasulye Yetiştiriciliği”" ve "Yeni Geliştirilen Kuru Fasulye Çeşitleri" konularında 103 kadın çiftçiye eğitim verilmiştir. Eğitimi tamamlayan kadın çiftçilere katılım belgesi düzenlenmiştir. Ayrıca üç farklı yerde üç kadın çiftçi ile 4'er dekarlık alanda üç farklı fasulye çeşidi ile kendi tohumları kullanılarak örnek uygulama yapılmıştır. Hasat yapılmadan önce “Tarla Günü” düzenlenmiştir.

\section{2. "Tarımda Kadın Girişimciliğin Güçlendirilmesi Programı" Kapsamında "Genç Girişimci Kadın Çiftçi” Projesi}

$\mathrm{Bu}$ proje ile tarımın her alanında eğitim çalışmalarına önem verilerek, kırsalda kadın girişimciliğinin özendirilmesi, desteklenmesi, üretici ve girişimci ruha sahip kadınların bilgilendirilmesi yoluyla tarımda kadın girişimciliğin en üst seviyeye çıkarılması hedeflenmektedir. Tarımda çalışan kadın işgücü; yenilikçi, kaynakları verimli kullanan, sürdürülebilir kalkınmaya katkı sağlayan rol model olarak değerlendirilmektedir. Bu kapsamda gerçekleştirilen proje sayesinde kırsal alanda çalışan genç kadın işgücünün istihdam olanaklarının arttırılması ve iş imkânlarının sürdürülebilir olması sağlanabilmektedir. Bu proje 
ile aynı zamanda köyden kente göçün azaltılması ve kırsal alandaki işgücünün ekonomik ve sosyal olanaklarının arttırılması amaçlanmaktadır.

Bu amaçlara ulaşabilmek için 2017 yılında 16 il belirlenmiştir. Afyonkarahisar bu 16 il (Amasya, Aydın, Batman, Bursa, Çorum, Erzincan, Giresun, Kahramanmaraş, Kars, Manisa, Mersin, Niğde, Osmaniye, Samsun, Tokat ) arasında yer almıştır. Belirlenen bu illerde kadın çiftçilere İŞKUR işbirliği ile istihdama yönelik sertifikalı 32 saat süren "Uygulamalı Girişimcilik Eğitimleri” verilmiştir.

Bu kapsamda 72 kadın çiftçi KOSGEB ve İŞKUR katkılarıyla 10-14 Nisan 2017 tarihleri arasında 32 saat Uygulamalı Girişimcilik Eğitimi almışlardır. Sonrasında düzenlenen «Proje Pazarı ve Sertifika Dağıtım Töreni» ile de projeler sergilenmiştir. İlk 3'e giren proje;

\section{Porselen Canlanıyor}

\section{Selda'nın Meyve Cipsleri}

\section{Ben Efe Köyünü Seviyorum Terk Etmedim, Çocuklarımda Terk Etmesin}

İlk 3'e giren bu projeler 15 Ekim 2017 tarihinde Türkiye finaline katılmışlardır. Bakanlık ve İl Müdürlüğ̈, kadın çiftçilerin kendi işlerinin patronu oldukları süreçte takip ve desteklerini sürdüreceklerini belirtmişlerdir.

Afyonkarahisar'da kadınlar tarafından hazırlanan projelerin şehre, bölgeye ve ülkeye kırsal ekonomi açısından katkısı oldukça önem taşımaktadır. Diğer yandan şehrin tarımsal yapısı ve yöresel ürün zenginliği dikkate alındığında bu katkının, sosyal ve ekonomik yönden kadınları güçlendireceği inkâr edilemez.

İl Müdürlüğ̈̈; 2016 yılında Afyonkarahisar da toplam 297 projeden 183'ü bayan girişimcilere ait olduğunu ve her bir girişimciye 30.000 TL hibe olmak üzere, toplamda 5.49 milyon TL hibe sağlandığını; 2017 yılında ise toplam 308 projeden 200'ü bayan girişimcilere aittir. Her bir girişimciye 30.000TL hibe olmak üzere, toplamda 6 milyon TL hibe sağlanmıştır. Takip eden yıllarda bu sayıların artacağı umut edilmektedir.

\section{Sonuç ve Öneriler}

Günümüz koşullarında kırsal alanda çalışan işgücünden kadın istihdamının faaliyetleri parasal olarak ekonomiye tam anlamıyla dâhil edilememektedir. Kadınlar ücretsiz aile işçisi olarak değerlendirilmektedirler. Gerek kırsal alanda sosyal, ekonomik yetersizlikler, gerekse kırsalda kadının birçok konuda kadın olmasından kaynaklanan donanım yetersizliği bu durumu desteklemektedir. Ancak çalışmamızda kırsalda yaşayan kadınların kendilerini yetiştirmelerine firsat verildiğinde ve kentte yaşayan kadınların sahip olduğu teknik, sosyal ve ekonomik destekler sunulduğunda kırsal girişimcilik alanında da oldukça başarılı olabildikleri görülmüştür. $\mathrm{Bu}$ bakımdan bakanlık tarafından oluşturulan kadının güçlendirilmesi planı önemli bir yol rehberi görevini üstlenmiştir. Sürdürülebilir kırsal kalkınmanın gerçekleştirilmesinde bu yol rehberi, her anlamda toplumun kadına bakış açısını ve de kırsalda kadının kendini aydınlanmış ve güçlenmiş hissetmesini sağlamaktadır. Kadınların ekonomik anlamda karşılaşmış oldukları engelleri rahat bir şekilde aşabilmeleri için örgütlü olmak ve kooperatifleşmenin önemi vurgulanmalıdır. Ancak kooperatifleşmenin mevzuat gereği Gıda Tarım ve Hayvancılık Bakanlığı bünyesinde değil, Gümrük ve Ticaret Bakanlığı bünyesinde oluşturularak sadece kurulduğu il ve ilçelerden üye kabulü sınırlandırılmasından muaf olabileceklerdir. Bu sayede farklı il ve ilçelerden üyelerin de kabul edilmesi sağlanabilecek ve daha geniş bir kitleye ulaşabilmeleri mümkün olabilecektir. 
Kırsalda kadın girişimciliği konusunda tüm kurum ve kuruluşların koordinasyon halinde faaliyetlerini sürdürmesi önem arz etmektedir. Ayrıca özellikle kırsalda kız çocuklarının eğitimi desteklenmelidir. İyi eğitim alarak yetişen kız çocukları, gelecekte güçlü kadınlar olarak toplumun hemen her kesiminde aktif rol almaktan çekinmeyeceklerdir. Kırsalda da kadın girişimcilerin örgütlenmeleri, erkek egemen toplum yapısında onlar için bir güç odağı oluşturacaktır. Aynı zamanda kendi aralarında güçlü bir iletişim ağı geliştirmelerinin de bu güç odağını destekleyeceği düşünülmektedir. Bir toplumda güçlü kadın özellikle güçlü girişimci kadın profilinin oluşturulması, başta kırsalda ve sonrasında ülkede ve dünyada sürdürülebilir kalkınmayı mümkün kılabilecektir. Ayrıca Türkiye ekonomisi tarıma dayalı bir ülke olmasına rağmen son zamanlarda kırsalda üretebileceği pek çok ürünü ithal etmektedir. Oluşturulan kalkınma planları ile kırsalda kadınların güçlenerek ekonomik kalkınmaya girişimcilik ruhunu da katmaları ile bu konuda da ilerleme kaydedilmesi mümkündür.

\section{Kaynakça}

D.P.T. (2000). "Kırsal Kalkınma ÖİK Raporu”, Sekizinci Beş Yıllık Kalkınma Planı, Ankara. Doğanay, F. (1993). Kırsal Kalkınma. DPT, Ankara.

Ecevit, Y. (1993). “Kadın Girişimciliğinin Yaygınlaşmasına Yönelik Bir Model Önerisi”, Kadını Girişimciliğe Özendirme ve Destekleme Paneli” , Devlet Bakanlığı Kadın ve Sosyal Hizmetler Müsteşarlığı Kadının Statüsü ve Sorunları, Genel Müdürlüğü Eğitim Serisi Yayın No:74, Ankara, ss.15-34.

Gülçubuk, B. vd. (2012). "Kırsalda Yoksulluğu Azaltmanın Bir Aracı Olarak "Kadın Girişimciliği”, 10.Ulusal Tarım Ekonomisi Kongresi, 5-7 Eylül, Konya, ss.358-366.

İlter, B. (2010). "Girişimcilik Sürecinde Kadın Girişimcilerin Karşılaştıkları Sorunların Analizi: Kagider Örneği”, Yayınlanmış doktora tezi, Adalet yayınevi, Ankara.

Kantar, M. (1999). “Girişimcilik ve Kırsal Kadınlar”, Tarım Ekonomisi Dergisi, 1999-4, ss.2942.

Moseley, M. J. (2003) . “Rural Development Principles and Practice”. First Published, London: SAGE Publications Ltd.

Müftüoğlu, T. ve Durukan, T. (2004). “Girişimcilik ve KOBİ’ler”, Gazi Kitabevi, Ankara.

Oğuz, C. (2015). “Türkiye’de Kırsal Kadınların İşgücüne Katılımı ve İstihdamı”, Uluslararası Katılımlı Sosyal Yaşam ve Kadın Sempozyumu Bildiri Özetleri, Konya.

Özgen, Ö. ve Ufuk H. (2011). "Kırsal Kesimde Kadın Eğitimi”, http://www.zmo.org.tr/resimler/ekler/6121d1f782d29b6_ek.pdf?tipi, ss.1063-1078, Erişim:24.05.2018

Proje 1. (2017). "Yeni Geliştirilen Kuru Fasulye Çeşitlerinin ve Yetiştirme Tekniklerinin Afyonkarahisar İli Kadın Çiftçilerine Yayımı" Projesi, T.C. Gıda Tarım ve Hayvancılık Bakanlığı. Afyonkarahisar İl Gıda Tarım ve Hayvancılık Müdürlüğü, Afyonkarahisar.

Proje 2. (2017). "Tarımda Kadın Girişimciliğin Güçlendirilmesi Programı Genç Girişimci Kadın Çiftçi Projeleri. Afyonkarahisar 2017” , T.C. Gıda Tarım ve Hayvancılık Bakanlığı, Afyonkarahisar İl Gıda Tarım ve Hayvancılık Müdürlüğü, Afyonkarahisar.

Soysal, A. (2013). "Kırsal Alanda Kadın Girişimciliği: Türkiye İçin Durum Değerlendirmesi”, Eskişehir Osmangazi Üniversitesi İIBF Dergisi, Nisan 8-1,ss. 163-189.

T.C. Gıda Tarım ve Hayvancılık Bakanlığı. (2012). “Kırsal Alanda Kadının Güçlendirilmesi Ulusal Eylem Planı (2012-2016)”,s s.12. 


\section{EXTENDED ABSTRACT}

\section{The Entrepreneurship of Women as an Alternative for the Sustainable Rural Development: A Sample of Afyonkarahisar}

The recent development of women's entrepreneurship is important for the sustainability of rural development. Although women play an active role in each phase of production, they do not fully benefit the benefits of development. This is because they lack education opportunities. Education conditions of women living in rural areas in our country are more difficult. Although female labour force contributes more in agricultural production than male labour force, these contributions are not reflected in official sources in economic terms. In order to ensure the development of the rural areas and the development of socio-economic development; women should have access to entrepreneurship activities, marketing activities and access to credit facilities. In this context, women, whose entrepreneurship is often ignored, should be encouraged in entrepreneurship and women's organizations should be supported more effectively. Today, sustainable rural development is gaining more importance than the economic development approach. In addition to today's conditions, future generations are taken into consideration in this concept.

Trainings were given about all fields of agriculture by Republic of Turkey Ministry of Agriculture and Forestry with the content of "Women's Empowerment in Rural Areas Action Plan". With these trainings, it is aimed to inform the women who are producers and entrepreneurs and to come to realize the projects that can be implemented. Afyonkarahisar Directorate of Provincial Agriculture and forestry in 2016, "Women Farmers Agricultural Extension Project was implemented. In project scope; The aim of this study is to enable women farmers to be more productive in the agricultural field, to benefit from agricultural innovations in a timely manner, to learn and apply new technologies, to use resources more effectively and to spread the innovations to female farmers. With the Young Entrepreneur Women Farmer Project within the scope of the Women Entrepreneurship Empowerment in Agriculture project, it is aimed to raise women entrepreneurship in agriculture by informing women with encouraging women entrepreneurship in rural areas. Female labour force in agriculture; It is considered as a role model that contributes to sustainable development. Thanks to this project, the employment opportunities of young women working in rural areas can be increased. With this project, it is aimed to reduce the migration from the village to the city and to increase the economic and social opportunities of the workforce in rural areas.

As a result; strengthen women's employment in rural areas, entrepreneurship practices should be encouraged to ensure that all institutions in the economy cooperate. This situation provides women living in rural areas to approach living standards of women living in urban areas. 